\title{
Papers
}

\section{The usefulness of tyrosinase in the immunohistochemical assessment of melanocytic lesions: a comparison of the novel T311 antibody (anti-tyrosinase) with S-100, HMB45, and A103 (anti-melan-A)}

\author{
K S Clarkson, I C Sturdgess, A J Molyneux
}

\begin{abstract}
Aim-To compare the sensitivity and staining pattern of the new immunohistochemical antibody to tyrosinase (T311) with S-100, HMB45, and the recently evaluated antibody to melan-A (A103) in a range of melanocytic lesions.

Method-Archival, formalin fixed, paraffin wax embedded sections from 50 benign and malignant melanocytic lesions were stained immunohistochemically with anti-tyrosinase, A103, S-100, and HMB45. They were scored semiquantitatively for the distribution and intensity of staining. Results-All melanomas, with the exception of desmoplastic melanoma, showed some staining with all four antibodies. Overall, T311 and A103 showed an intermediate sensitivity compared with that of S-100 and HMB45. T311 stained most benign and malignant lesions strongly and diffusely with minimal background staining. Immunoreactivity was found to be patchy in some naevi, with weak or absent staining of the mature melanocytes. A103 showed strong and diffuse staining of all benign lesions and most melanomas with minimal background staining. S-100 was the most sensitive, with diffuse staining of most lesions, including desmoplastic and metastatic melanoma, but lacked specificity. HMB45 was the least sensitive antibody, frequently demonstrating patchy staining with absent staining in some benign naevi.

Conclusions-S-100 remains the most sensitive marker of melanocytes. However, because of its lack of specificity, it should be used with at least one other more specific antibody. HMB45 is more specific, but lacks sensitivity; T311 is a reliable marker of melanocytes in paraffin wax embedded sections and is worth consideration for use in a staining panel, although it shows no additional benefit over A103.

(f Clin Pathol 2001;54:196-200)
\end{abstract}

Keywords: T311 (anti-tyrosinase); A103 (anti melan-A); immunohistochemistry; melanocytic lesions

The heterogeneous histological appearance of malignant melanoma has led to the frequent use of immunohistochemistry in formulating a diagnosis. S-100 and HMB45 are currently the most frequently used antibodies. S-100 is a polyclonal antibody raised against a relatively non-specific neuroendocrine marker (S-100 protein) and HMB45 is a monoclonal antibody against group 100 protein. S-100 is a sensitive marker of melanocytes but lacks specificity, ${ }^{12}$ whereas HMB45 is a more specific marker that lacks sensitivity. ${ }^{355}$ Therefore, a marker (or markers) that is sensitive and has improved specificity would be useful, especially when a panel of immunohistochemical markers is contemplated.

A monoclonal IgG antibody (clone A103) that detects melan-A (a melanocytic differentiation antigen) is such an antibody. It has recently been evaluated ${ }^{6-8}$ and found to exhibit a sensitivity between that of S-100 and HMB45.

Tyrosinase is an enzyme involved in the initial stages of melanin biosynthesis in melanocytes and melanoma cells. ${ }^{9}$ Detection of tyrosinase mRNA in the peripheral blood ${ }^{1011}$ and lymph nodes ${ }^{12}{ }^{13}$ is possible by the reverse transcriptase-polymerase chain reaction (RTPCR), and this has been confirmed as a useful prognostic marker in the staging of malignant melanoma. Recently, a monoclonal IgG antibody T311 that detects tyrosinase expression in paraffin wax embedded sections has become available. Previous work has shown T311 to be useful in the detection of amelanotic metastatic melanoma $^{14}$ and conventional melanoma ${ }^{15}$ in paraffin wax embedded sections.

In our study, we compared the immunoreactivity of T311 with the profiles of the established antibodies S-100 and HMB45 and the more recently evaluated antibody to melan-A (A103) in a range of benign and malignant melanocytic lesions. 
Table 1 Summary of the intensity and distribution of melanocyte staining with T311, A103, S-100, and HMB45 in benign melanocytic lesions

\begin{tabular}{|c|c|c|c|c|}
\hline & T311 & $A 103$ & $S-100$ & $H M B 45$ \\
\hline Compound naevus (4) & $\begin{array}{l}\text { ++ Junctional and superficial dermal cells }+ \text { deep } \\
\text { dermal cells }(2) \\
++ \text { Junctional and superficial dermal cells with no } \\
\text { staining deep dermal cells }(2)\end{array}$ & ++ All cells $(4)$ & ++ All cells $(4)$ & $\begin{array}{l}\text { + Junctional and superficial dermal cells (2) } \\
\text { No staining (2) }\end{array}$ \\
\hline Intradermal naevus (3) & $\begin{array}{l}\text { + All cells (1) } \\
++ \text { Superficial dermal cells }(2)\end{array}$ & ++ All cells $(3)$ & ++ All cells $(3)$ & $\begin{array}{l}\text { ++ Superficial dermal cells (1) } \\
\text { No staining (2) }\end{array}$ \\
\hline Junctional naevus (3) & ++ All cells (3) & ++ All cells $(3)$ & ++ All cells $(3)$ & $\begin{array}{l}++ \text { All cells }(2) \\
+ \text { All cells }(1)\end{array}$ \\
\hline Blue naevus ( 3 ) & $\begin{array}{l}++ \text { All cells }(2) \\
++ \text { Deep dermal cells }+ \text { superficial dermal cells }(1)\end{array}$ & ++ All cells $(3)$ & $\begin{array}{l}++ \text { All cells }(2) \\
+ \text { All cells }(1)\end{array}$ & $\begin{array}{l}++ \text { All cells }(1) \\
++ \text { Deep dermal cells no staining of } \\
\text { superficial dermal cells }(2)\end{array}$ \\
\hline Spitz naevus (4) & ++ All cells $(4)$ & ++ All cells $(4)$ & ++ All cells $(4)$ & $\begin{array}{l}++ \text { All cells }(2) \\
+ \text { Superficial dermal cells }(2)\end{array}$ \\
\hline $\begin{array}{l}\text { Spindle cell naevus of } \\
\text { Reed (4) }\end{array}$ & ++ All cells $(4)$ & ++ All cells $(4)$ & ++ All cells $(4)$ & $\begin{array}{l}++ \text { All cells }(3) \\
+ \text { All cells }(1)\end{array}$ \\
\hline Dysplastic naevus (4) & $\begin{array}{l}++ \text { All cells }(3) \\
+ \text { All cells }(1)\end{array}$ & ++ All cells $(4)$ & ++ All cells $(4)$ & $\begin{array}{l}++ \text { All cells }(3) \\
+ \text { All cells }(1)\end{array}$ \\
\hline
\end{tabular}

Materials and methods

Archival formalin fixed, paraffin wax embedded sections from a range of melanocytic lesions were selected at random. A total of 50 melanocytic lesions were included comprising 25 benign lesions, namely: compound naevus (four), intradermal naevus (three), junctional naevus (three), blue naevus (three), Spitz naevus (four), spindle cell naevus of Reed (four), and dysplastic naevus (in this study a naevus showing architectural and cytological atypia) (four); and 25 malignant lesions, namely: nodular melanoma (five), superficial spreading melanoma (nine), metastatic melanoma (five), desmoplastic melanoma (two), lentigo maligna melanoma (two), and acral lentiginous melanoma (two).

The $3 \mu \mathrm{m}$ thick sections were cut and floated on to $3^{\prime}$ aminopropyltriethoxysilane (APES) coated slides and dried overnight at $37^{\circ} \mathrm{C}$. The sections were dewaxed and rehydrated in a graded series of alcohols. Endogenous peroxidase was blocked by preincubation with $0.6 \%$ hydrogen peroxide for 15 minutes. For antigen retrieval, T311 and A103 sections were microwaved for 20 minutes $(2 \times 10$ minutes $)$ in Vector antigen unmasking solution (Vector, Peterborough, UK) at $\mathrm{pH}$ 6.0. The $\mathrm{S}-100$ and HMB45 sections were incubated with trypsin (one Shandon trypsin tablet dissolved in $50 \mathrm{ml}$ of distilled water) for 20 minutes at $37^{\circ} \mathrm{C}$. All sections were then incubated with T311 (Novocastra, Newcastle upon Tyne, UK; 1/25), A103 (Novocastra; 1/25), S-100 (Dako, Ely, UK; 1/3000), and HMB45 (Dako; 1/200) for 60 minutes (T311, A103) or 30 minutes (S-100, HMB45). The slides were then developed using a standard indirect avidin-biotin complex (ABC) technique (Vectastain Elite ABC kit; Vector) on a Cadenza (Shandon, Runcorn, UK) automated immunostainer.

Cases were assessed semiquantitatively by two independent pathologists. The intensity and distribution of melanocyte staining in benign lesions and melanoma cell staining in malignant lesions was recorded for each antibody. In cases where there was a discrepancy in scoring between the pathologists a consensus score was agreed.

\section{Results}

Tables 1 and 2 summarise the staining profiles of the antibodies.

With the exception of desmoplastic malignant melanoma all four antibodies showed some immunoreactivity in all the melanoma cases.

T311 showed reliable staining of both benign and malignant melanocytic lesions with minimal background staining. Immunoreactivity was found to be patchy in some benign naevi, with weak or absent staining of the mature melanocytes but strong staining of the junctional and superficial dermal cells (fig 1A). There was diffuse staining of all malignant melanomas except for patchy staining in two of the metastatic melanomas (fig 1B) and an absence of staining in both desmoplastic melanomas.

Table 2 Summary of the intensity and distribution of melanoma cell staining for T311, A103, S-100, and HMB45 in malignant melanocytic lesions

\begin{tabular}{|c|c|c|c|c|}
\hline & T311 & A103 & $S-100$ & $H M B 45$ \\
\hline Nodular melanoma (5) & $\begin{array}{l}++ \text { All cells }(4) \\
+ \text { All cells }(1)\end{array}$ & $\begin{array}{l}\text { ++ All cells (2) } \\
\text { + All cells (1) } \\
\text { ++ Patchy (1) } \\
\text { + Patchy (1) }\end{array}$ & $\begin{array}{l}++ \text { All cells (3) } \\
+ \text { All cells (1) } \\
\text { ++ Patchy (1) }\end{array}$ & $\begin{array}{l}++ \text { All cells (1) } \\
++ \text { Patchy (1) } \\
+ \text { Patchy (3) }\end{array}$ \\
\hline Superficial spreading melanoma (9) & $\begin{array}{l}++ \text { All cells }(8) \\
+ \text { All cells }(1)\end{array}$ & $\begin{array}{l}++ \text { All cells }(8) \\
+ \text { Patchy (1) }\end{array}$ & $\begin{array}{l}++ \text { All cells }(6) \\
+ \text { All cells }(2) \\
+ \text { Patchy }(1)\end{array}$ & $\begin{array}{l}\text { ++ All cells (5) } \\
+ \text { All cells }(1) \\
\text { ++ Patchy }(2) \\
+ \text { Patchy }(1)\end{array}$ \\
\hline Metastatic melanoma (5) & $\begin{array}{l}++ \text { All cells (3) } \\
\text { ++ Patchy (1) } \\
+ \text { Patchy (1) }\end{array}$ & $\begin{array}{l}++ \text { All cells (3) } \\
++ \text { Patchy (1) } \\
+ \text { Patchy }(1)\end{array}$ & ++ All cells $(5)$ & $\begin{array}{l}++ \text { All cells }(4) \\
++ \text { Patchy (1) }\end{array}$ \\
\hline Desmoplastic melanoma (2) & No staining (2) & No staining (2) & ++ All cells $(2)$ & No staining (2) \\
\hline Lentigo maligna melanoma (2) & ++ All cells $(2)$ & ++ All cells $(2)$ & ++ All cells (2) & ++ All cells $(2)$ \\
\hline Acral lentiginous melanoma (2) & ++ All cells $(2)$ & ++ All cells $(2)$ & ++ All cells $(2)$ & $\begin{array}{l}++ \text { All cells }(1) \\
++ \text { Patchy }(1)\end{array}$ \\
\hline
\end{tabular}

Staining: +, weak; ++, strong. 

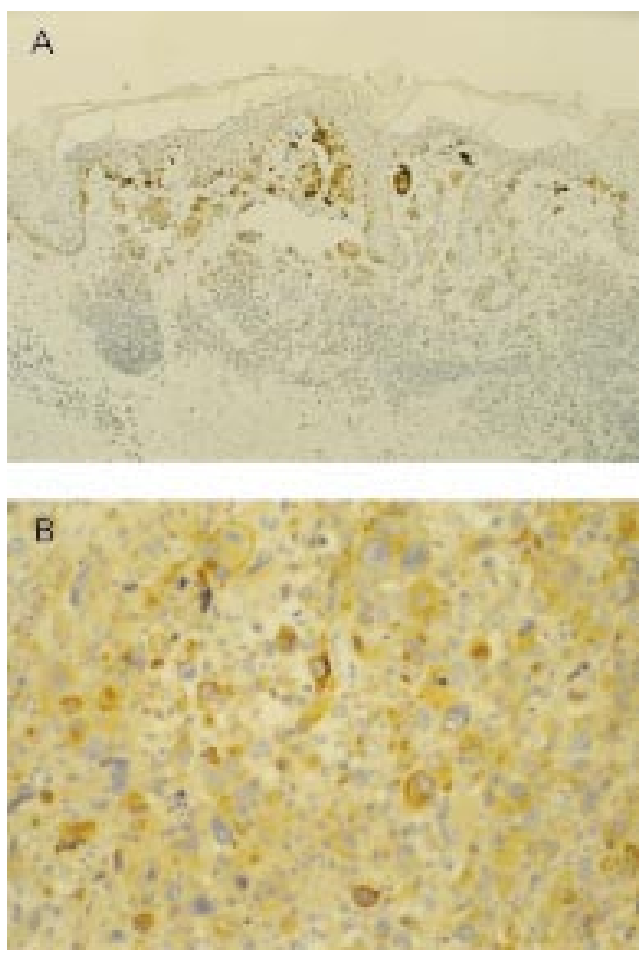

Figure 1 (A) Compound naevus: T311 stains junctional and superficial dermal melanocytes strongly, with weak staining of the mature component. (B) Metastatic melanoma in a lymph node: T311 shows strong patchy staining.

A103 demonstrated strong diffuse staining of all melanocytes in the benign lesions (fig $2 \mathrm{~A}$ ). Although a more variable pattern was seen in the malignant melanomas, A103 still stained 18 of the 25 cases diffusely. Patchy staining was seen in only five lesions, and there was an absence of staining in both desmoplastic melanomas. Background staining was minimal in all cases.

Our study confirmed the established staining pattern for S-100 protein, with strong diffuse

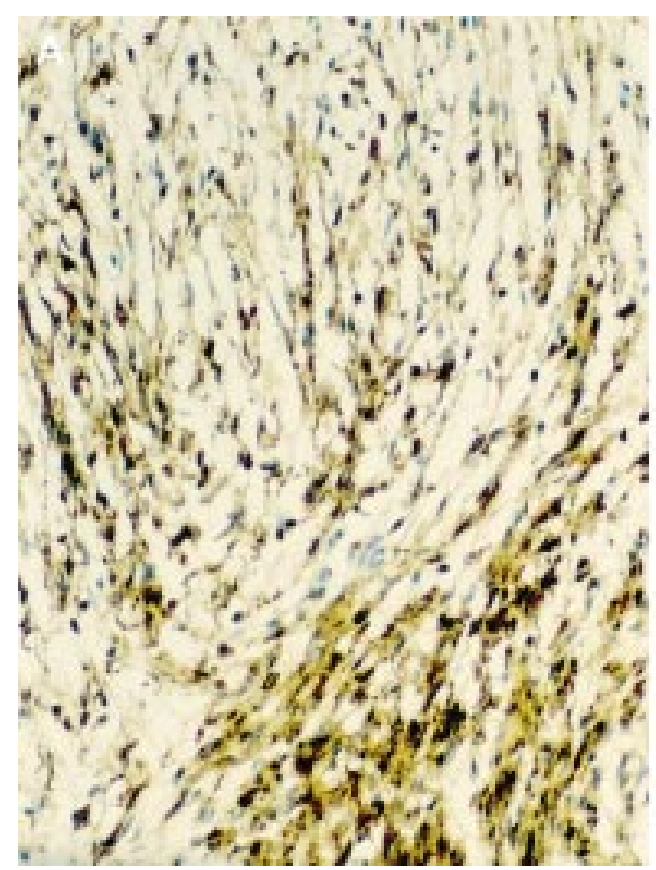

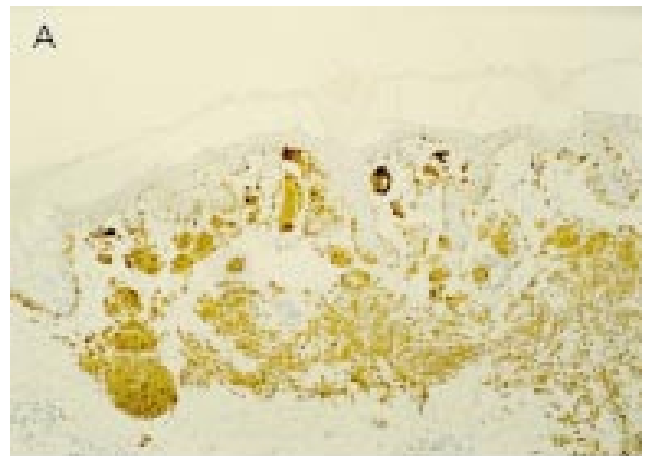

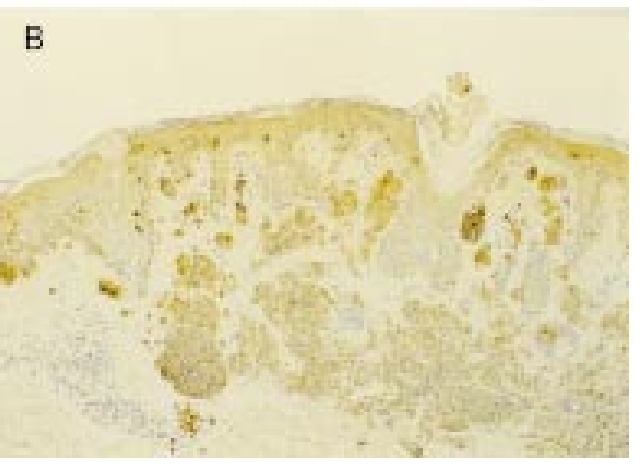

Figure 2 (A) Compound naevus: A103 shows strong diffuse staining of all melanocytes. (B) Compound naevus: S-100 stains melanocytes strongly and diffusely.

staining of virtually all benign lesions (fig $2 \mathrm{~B}$ ) and most malignant lesions. Non-specific background staining, particularly highlighting Langerhans cells, nerve tissue, and skin appendages, was sometimes problematic. S-100 was the only antibody to stain desmoplastic malignant melanomas (fig 3) and was the most reliable for metastatic melanoma in lymph nodes.

The HMB45 antibody showed absent or patchy staining of the compound and intradermal naevi, with staining confined to the

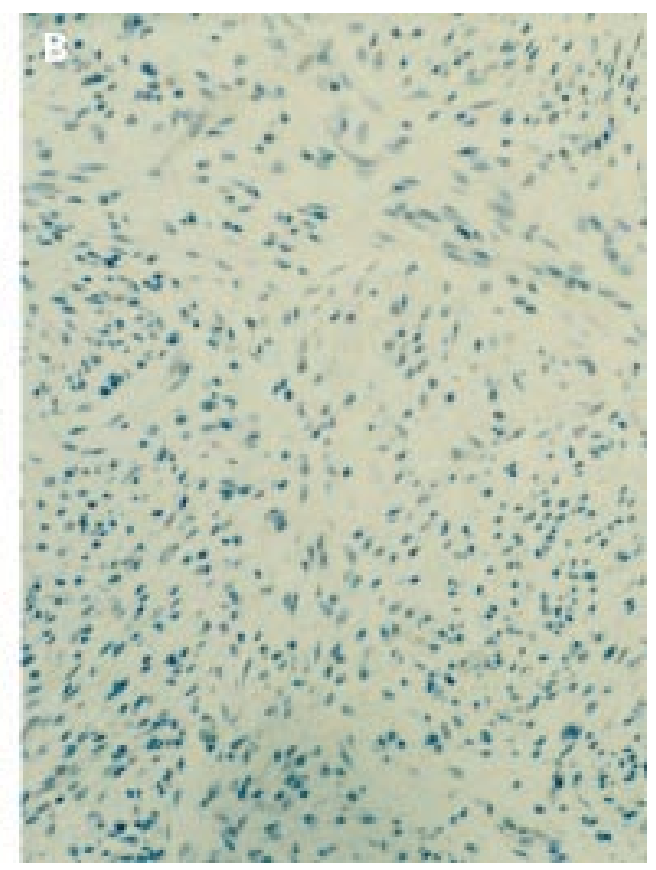

Figure 3 Desmoplastic melanoma. (A) S-100 showing strong diffuse staining. (B) No staining with T311. 


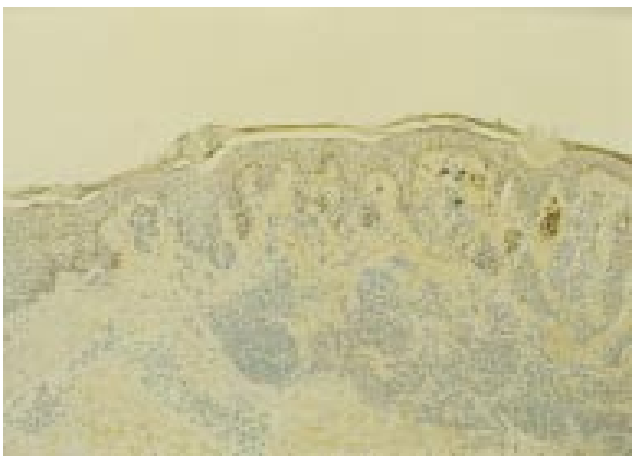

Figure 4 Compound naevus. HMB45 showing immunoreactivity of the junctional and superficial dermal melanocytes with no staining of the mature component.

junctional and superficial dermal component (fig 4). The immunoreactivity of melanocytes in malignant melanoma was variable, with patchy staining in nine and a diffuse pattern in 14 of the 25 cases. There was no staining of the two desmoplastic melanomas. Non-specific background staining in all lesions was minimal.

\section{Discussion}

The diagnosis of both primary and secondary melanoma is usually extremely important clinically but can present difficulties both for the general histopathologist and the "expert". ${ }^{16}$ Although currently there is no antibody that can discriminate between benign and malignant melanocytic lesions, immunohistochemistry has an important place in the assessment of some cases. For example, the true architecture of melanocytic skin lesions may be difficult to assess when there is a heavy associated dermal inflammatory cell infiltrate. Even when a diagnosis of cutaneous melanoma can be made with confidence on routine sections, a prominent associated lymphohistiocytic infiltrate might also make the assessment of dermal invasion problematic. Because the depth of invasion (Breslow thickness) is the most powerful prognostic factor, accurate evaluation of this parameter is vital in melanoma diagnosis. This may only be possible with the aid of immunohistochemistry, using relatively specific and sensitive markers for melanocytes. Secondary melanoma may present in advance of an occult primary or many years after the primary diagnosis, appearances may be very variable, and melanin is often sparse or absent. In this context, immunohistochemistry may confirm the primary origin. For these reasons, immunohistochemistry is commonly used as an adjunct to routine light microscopy in the diagnosis (and staging) of primary and secondary melanomas.

S-100 and HMB45 have been widely used in the immunohistochemical assessment of melanomas and, in common with previous studies, we found the staining patterns predictable. $^{361718}$ There are problems in interpretation using the S-100 and HMB45 dual panel approach, however, and these are related to sensitivity and specificity. Previous studies have confirmed the sensitivity of S-100 for naevus cells ${ }^{1920}$ and malignant melanoma, but have also shown its lack of specificity, staining a wide range of other tissues. ${ }^{12}$ This lack of specificity is related to the polyclonal nature of the antibody and its reactivity with both $\alpha$ and $\beta$ subunits of the (cow brain) protein it was raised against. Two particular problems in melanoma diagnosis are related to its staining of neural tissues and histiocytes. The former staining may confuse the issue in secondary melanoma diagnosis where there is a spindle cell growth pattern because tumours of neural origin may be considered. Equally, in primary melanoma, the assessment of invasion can be hampered by the staining of histiocytes in the associated dermal inflammatory cell infiltrate. In contrast, the monoclonal antibody HMB45 has been raised against group 100 protein, ${ }^{21}{ }^{22}$ is localized to premelanosomes ultrastructurally, ${ }^{23}$ and is a more specific marker of melanocytes than S-100.-5 However, the antibody is not absolutely specific because immunoreactivity has been described to normal breast epithelium, some carcinomas of the breast, normal sweat glands, and some sweat gland tumours. ${ }^{24} 25$ The improved specificity is also at the expense of sensitivity, with variable and heterogeneous staining even within typical melanomas and absent staining in some benign naevi, particularly the dermal component. ${ }^{4}$ Therefore, there is a need for an alternative specific marker of melanocytes with greater sensitivity than HMB 45.

A recently evaluated antibody to melan-A (A103), a melanocytic differentiation antigen, was found to show a similar staining pattern to S-100 for melanocytes, with the exception of desmoplastic, spindle cell, and metastatic melanoma, where staining for melan-A was less sensitive. ${ }^{6}$ However, A103 is more specific than S-100; to date, it has only shown immunoreactivity with melanocytes and steroid producing tumours. ${ }^{726}$ In our study, A103 stained all the benign lesions and most of the melanomas strongly and diffusely with minimal background staining. There was patchy staining in a few melanomas and an absence of immunoreactivity in desmoplastic melanomas, but all the remaining malignant lesions stained strongly and diffusely.

Tyrosinase is an enzyme involved in the initial stages of melanin biosynthesis and a monoclonal antibody to this molecule has become available for use on paraffin wax sections (T311). A previous study ${ }^{15}$ found T311 to be $94 \%$ sensitive for melanomas overall, but the sensitivity was correlated inversely with clinical stage. In our study, T311 stained most benign and malignant lesions strongly and diffusely, with minimal background staining. Although reliable in its staining of most melanomas, there was a tendency for weak or absent staining of the mature melanocytes in intradermal and compound naevi.

Although only two desmoplastic melanomas were included, a similar staining pattern to that described previously ${ }^{6718}$ was seen. S-100 stained strongly and diffusely but T311, A103, and HMB45 showed no immunoreactivity.

Our study found S-100 to be the most reliable antibody for metastatic melanoma in lymph nodes with strong diffuse staining of all 
cases, confirming previous observations. ${ }^{6} \mathrm{~T} 311$ and A103 have an intermediate sensitivity to S-100 and HMB45, being less sensitive than S-100 in the staining of metastatic and desmoplastic melanomas. T311, A103, and HMB45 are more specific than S-100 for melanocytes, and of these A103 appears the most sensitive, followed by T311. The profile of T311 has yet to be evaluated fully on a range of tissues but a previous study has found it to be specific for melanocytes only. ${ }^{14}$ Although S-100 still appears to be the most sensitive marker of melanocytes available, problems with specificity are encountered. In diagnostic surgical pathology practice where morphology and conventional stains alone do not provide the answer, we would advocate the use of a panel of antibodies. The complementary use of melanocyte specific antibodies together with S-100 can be of undoubted benefit. A103, and to a lesser extent T311, show greater sensitivity than HMB45 for melanocytes and are especially useful in the assessment of heavily inflamed or regressing skin lesions. Used in this context, both of these antibodies will highlight the architecture of the lesion and will even stain single melanocytes within the associated inflammatory infiltrate. In conclusion, tyrosinase has been shown to be a sensitive, reliable marker of melanocytes in paraffin embedded sections. Although not as sensitive as A103, T311 is worth consideration when using a panel of antibodies to assess difficult melanocytic lesions.

1 Takahashi $\mathrm{K}$, Isobe $\mathrm{T}$, Ohtsuki $\mathrm{Y}$, et al. Immunohistochemical study on the distribution of alpha and beta subunits of $\$ 100$ protein in human neoplasms and normal tissues. Virchows Arch B Cell Pathol Incl Mol Pathol 1984;45:385-96.

2 Vanstapel MJ, Gatter KC, Wolf-Peeters C, et al. New site of human S100 immunoreactivity detected with monoclonal antibodies. Am f Clin Pathol 1986;85:160-8.

3 Skelton HG, Smith KJ, Barrett TL, et al. HMB45 staining in benign and malignant melanocytic lesions. A reflection of cellular activation. Am f Dermatopathol 1991;13:543-50.

4 Gown AM, Vogel AM, Hoak D, et al. Monoclonal antibodies specific for melanocytic tumours distinguish subpopulations of melanocytes. Am ₹ Pathol 1988;123:195-203.

5 Smoller BR, McNutt NS, Hsu A. HMB-45 recognises stimulated melanocytes. F Cutan Pathol 1989;16:49-53.

6 Blessing K, Sanders DSA, Grant JJH. Comparison of immunohistochemical staining of the novel antibody
melan-A with S100 protein and HMB45 in malignant melanoma and melanoma variants. Histopathology 1998;32: $139-46$

7 Jungbluth AA, Busam KJ, Gerald WL, et al. A103 - an antimelan-A monoclonal antibody for the detection of malignant melanoma in paraffin-embedded tissues. Am $\mathcal{F}$ Surg Pathol 1998;22:595-602.

8 Busam KJ, Chen YT, Old LJ, et al. Expression of melan-A (MART1) in benign melanocytic nevi and primary cutaneous malignant melanoma. Am f Surg Pathol 1998;22:97682.

9 Kwon BS. Pigmentation genes: the tyrosinase gene family and the pmel 17 gene family. Invest Dermatol 1993;100: $134-40$

10 Kunter U, Buer J, Probst M, et al. Peripheral blood tyrosinase messenger RNA detection and survival in malignant melanoma. F Natl Cancer Inst 1996;88:590-4.

11 Stevens GL, Scheer WD, Levine EA. Detection of tyrosinase mRNA from the blood of melanoma patients. Cancer Epidemiol Biomarkers Prev 1996;5:293-6.

12 Shivers SC, Wang X, Li W, et al. Molecular staging of malignant melanoma: correlation with clinical outcome. $f A M A$ 1998;280:1410-15.

13 Blaheta HJ, Schittek B, Breuninger H, et al. Lymph node micrometastases of cutaneous melanoma: increased sensitivity of molecular diagnosis in comparison to immunohistochemistry. Int $\mathcal{F}$ Cancer 1998;79:318-23.

14 Kaufmann O, Koch S, Burghardt J, et al. Tyrosinase, melan-A, and KBA62 as markers for the immunohistochemical identification of metastatic amelanotic melanomas on paraffin sections. Mod Pathol 1998;11:740-6.

15 Hofbauer GF, Kamarashev J, Geertsen R, et al. Tyrosinase immunoreactivity in formalin-fixed, paraffin-embedded primary and metastatic melanoma: frequency and distribution. F Cutan Pathol 1998;25:204-9.

16 Diagnosing melanoma. Bandolier Jan 1998;47:7.

17 Bacchi CE, Bonetti F, Pea M et al. HMB45. A review. Appl Immunohistochem 1996;4:73-85.

18 Longacre TA, Egbert BM, Rouse RV. Desmoplastic and spindle-cell malignant melanoma. An immunohistochemical study. Am F Surg Pathol 1996;20:1489-500.

19 Busam KJ, Barnhill RL. Special stains in the evaluation of melanocytic lesions [letter]. Melanoma 1994;12:1-4.

20 Ruiter D, Broeker EB. Immunohistochemistry in the evaluation of melanocytic tumours. Semin Diagn Pathol 1993;10: $76-91$.

21 Adema GJ, de-Boer AJ, van-'t-Hullenaar R, et al. Melanocyte lineage-specific antigens recognized by monoclonal antibodies NKI beteb, HMB-50 and HMB-45 are encoded by a single cDNA. Am f Pathol 1993;143:1579-85.

22 Adema GJ, de-Boer AJ, Vogel AM, et al. Molecular characterization of the melanocytic lineage-specific antigen gp 100. 7 Biol Chem 1994;269:20126-33.

23 Gooverts G, Buyssens N. Nevus cell maturation or atrophy? Am $\mathcal{F}$ Dermatopathol 1988;10:20-7.

24 Bonetti F, Colombari R, Manfrin E, et al. Breast carcinoma positive for the melanoma marker (HMB45). HMB45 immunoreactivity in normal and neoplastic breast. Am $\mathcal{F}$ Clin Pathol 1989;92:91-5.

25 Kanitakis J, Hermier C, Chouvet B, et al. Reactivity of HMB45 monoclonal antibody with sweat gland tumours of the skin. Acta Derm Venereol 1991;71:426-8.

26 Busam KJ, Iversen K, Coplan KA, et al. Immunoreactivity for A103, an antibody to melan-A (MART1) in adrenocortical and other steroid tumours. Am F Surg Pathol 1998;22: $57-63$.

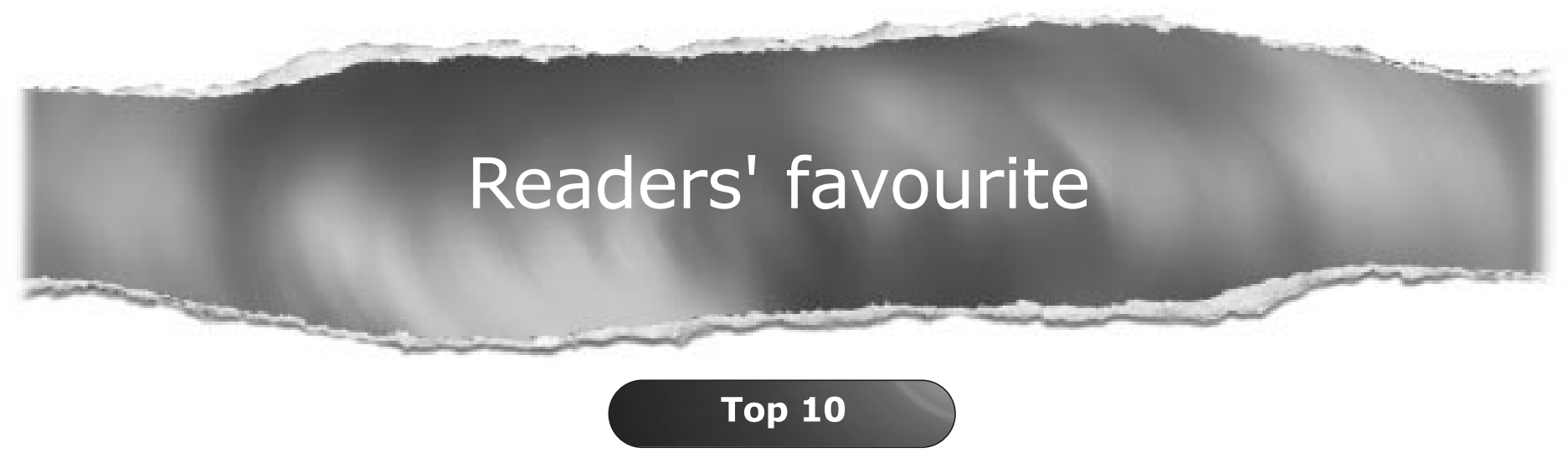

Click on the "Top 10" button on the homepage to see which are the best read articles each month

www.jclinpath.com 